This item was submitted to Loughborough's Research Repository by the author.

Items in Figshare are protected by copyright, with all rights reserved, unless otherwise indicated.

\title{
Institutional shaping of interagency working: managing tensions between collaborative working and client confidentiality
}

PLEASE CITE THE PUBLISHED VERSION

PUBLISHER

Oxford University Press / @ The Authors

VERSION

AM (Accepted Manuscript)

\section{LICENCE}

CC BY-NC-ND 4.0

\section{REPOSITORY RECORD}

6, Perri, Christine Bellamy, Charles Raab, Adam P. Warren, and Catherine Heeney. 2019. "Institutional Shaping of Interagency Working: Managing Tensions Between Collaborative Working and Client Confidentiality". figshare. https://hdl.handle.net/2134/4482. 
This item was submitted to Loughborough's Institutional Repository (https://dspace.lboro.ac.uk/) by the author and is made available under the following Creative Commons Licence conditions.

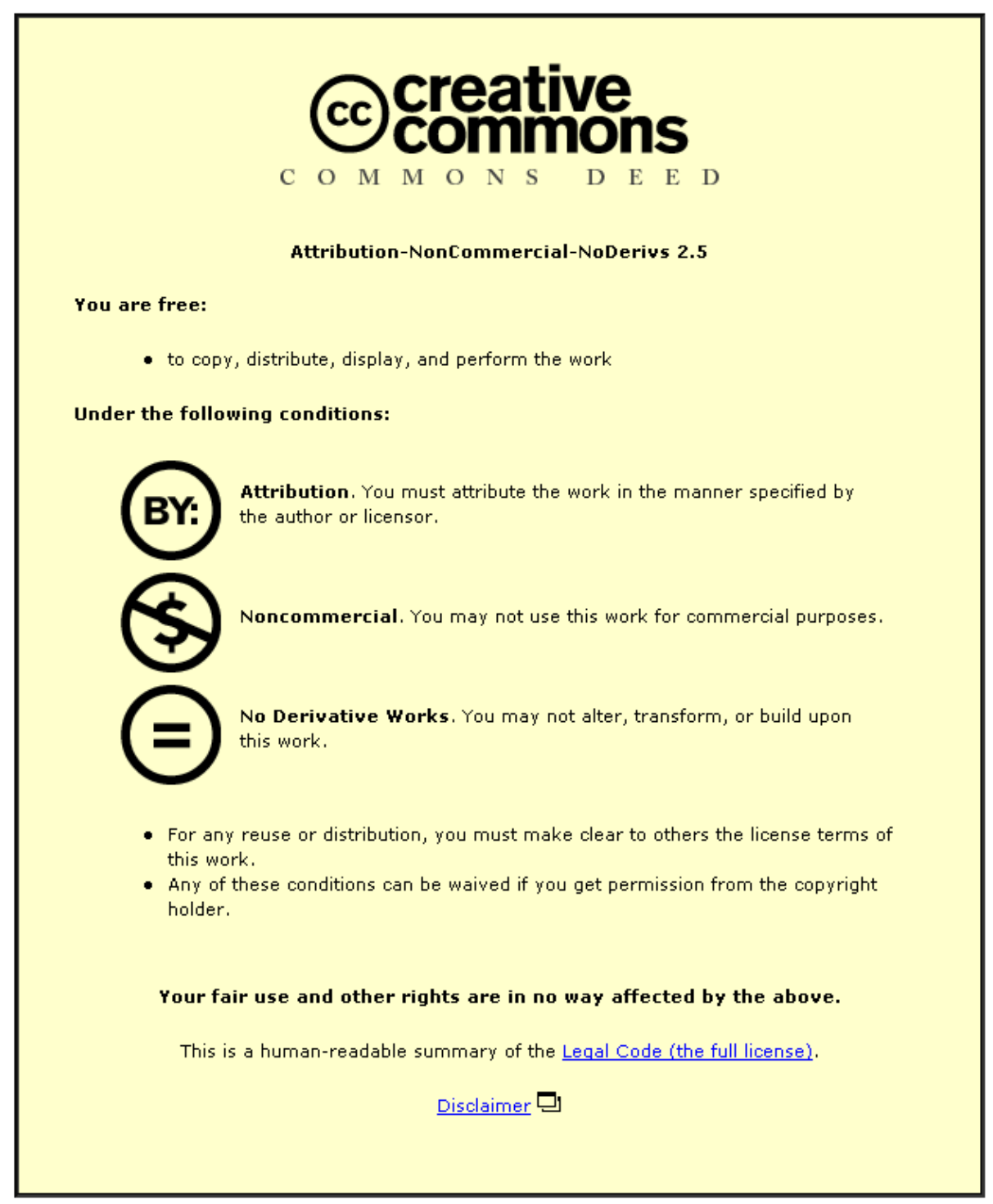

For the full text of this licence, please go to: http://creativecommons.org/licenses/by-nc-nd/2.5/ 


\title{
Article
}

\section{Institutional shaping of inter-agency working: managing tensions between collaborative working and client confidentiality}

\author{
by \\ Perri 6, Nottingham Trent University \\ Christine Bellamy, Nottingham Trent University \\ Charles Raab, University of Edinburgh \\ Adam Warren, Loughborough University \\ Cate Heeney, Oxford University.
}

Corresponding author. Perri 6, Professor of Social Policy, Nottingham Trent University, Burton Street, Nottingham, NG1 4BU; tel 0115848 5537; e-mail: Perri.6@ntu.ac.uk 
Abstract

Tensions between imperatives for sharing of information about clients, patients and offenders and those for confidentiality and privacy have become a prominent but unresolved issue in British public policy in the context of greater pressures towards inter-agency collaboration. This article analyses empirical data from a major, ESRC-funded research project designed to provide the first systematic evidence about the ways in which local partnerships working in sensitive policy fields in England and Scotland attempt to strike settlements between sharing and confidentiality, and discusses the impact of national government's attempts to increase formal regulation of their information-sharing practices. To do this, the project has developed a methodology to operationalise neo-Durkheimian institutional theory, and demonstrates that theory in this tradition has the power to identify and explain patterns of information sharing styles adopted in local collaborative working. The overall conclusion is that the stronger assertion of formal regulation by national government may well be leading to the greater prominence of hierarchical institutional forms, but it may also be associated with the counter-assertion of other institutional forms, too, and in ways that may reinforce problems that greater regulation is intended to address. In particular, we show that increased formal regulation does not always lead frontline staff to be more confident about local information sharing practices, nor should it lead observers to be more confident that data sharing practices will be more transparent or consistent from locality to locality. 


\section{Introduction}

For some years, governments in the UK have increased pressure on public services to share personal information with other agencies about the people with whom they work, especially in such fields as health and social care, child protection, crime reduction and public protection against dangerous offenders. ${ }^{1}$ Inter-agency information sharing has become a major political issue in the UK as a result of a series of prominent cases where agencies failed to share information, with disastrous consequences. These cases include several where children died at the hands of their guardians despite being known to more than one agency (e.g., Laming 2003), a case where a person suffering from paranoid schizophrenia lost touch with his supervising agencies and murdered a passing stranger at an underground railway station (Ritchie et al. 1994), and the case of Ian Huntley, who had been the subject of a number of unproven allegations of sex crimes against young girls, and was subsequently employed as a school janitor in another policing area where he killed two schoolgirls (Bichard 2004). In many of these cases, managers attempted to deflect criticism by arguing that confidentiality rules or data protection law prevented them from sharing information.

As a result, in the UK, the general thrust of recent government policy has been to increase pressures for sharing information in response to a widespread view that the cases cited above resulted from excessive and inappropriate deference to privacy laws and confidentiality norms. So heavy is the emphasis now being placed on this issue by national policy-makers, that a recent White Paper (Cabinet Office, 2005) placed the enhancement of information-sharing at the core of the egovernment project. A Cabinet Committee, MISC 31, was set up in February 2006 to 'develop the Government's strategy on data-sharing across the public sector' (Cabinet Office, 2006a). In addition, a new, high-level outline strategy for government information-sharing was announced in September 2006 (DCA, 2006) and a 'comprehensive plan' is promised for April 2007. Moreover, the new Social Exclusion Action Plan (Cabinet Office, 2006b), also published in September 2006, was said to 'go 
hand in hand' (Cabinet Office, 2006c) with that information sharing strategy (DCA, 2006). A new consultation paper on combating serious and organised crime also proposes major extensions of information sharing (Secretary of State for the Home Department, 2006).

At the same time, it is recognised that there are often good reasons to protect the confidentiality of clients who may include children thought to be at risk of abuse, other vulnerable people, health care patients, and convicted, suspected or potential offenders, and also their families and associates. Not only are personal data protected by the human right to privacy, or by data protection legislation, but confidentiality is often required to achieve desired service outcomes. For example, doctors and social workers preserve confidentiality in order to promote frankness between therapist and client, law enforcement agencies preserve confidentiality to safeguard their sources and operations, and a wide range of professionals share information responsibly only in contexts where there is shared tacit understanding about its reliability and implications, especially when that information is based on 'hunch' or other kinds of soft or uncorroborated data. As we have discussed elsewhere (6 et al. 2005, Bellamy et al. 2005a, 2005b), a strong edifice of legal strictures (e.g., the Data Protection Act 1998) and professional norms therefore govern the disclosure of identifiable personal information by and within public services, but in so doing create significant tensions between imperatives for sharing and imperatives to protect client confidentiality. This important but difficult issue has recently received a great deal of attention in the UK (e.g., DCA 2003; E-government unit 2005; NHS 2003; PIU 2002) as national policymakers have tried to reduce this tension by introducing new legislation, making rules, issuing guidance, and specifying new institutional roles and procedures for the benefit of service managers and frontline professionals who are charged with making difficult decisions on a day to day basis. The assumption driving all this activity is that clearer regulation of this kind will promote greater confidence amongst frontline staff in managing the risks to confidentiality associated with data sharing, and thus increase its volume overall. 
It would be too much to expect that such initiatives would produce uniformity of local practices, or even that they will inevitably shift all local agencies decisively and consistently to engage in more data sharing. There are reasons well documented by empirical research on inter-agency collaboration (see e.g., 6 et al. 2002; Challis et al. 1988; Sullivan and Skelcher 2002) to suppose that some agencies will fail to share information - even when others might consider it appropriate to do so - including professional rivalries, distrust between departments or agencies, lack of inter-operable information systems, incompatible rules and norms and different standards by which thresholds for sharing are defined or measured. The fact that such factors continue to inhibit data sharing is borne out by a series of recent studies of practices in various policy sectors (e.g., Baines et al. 2004; Cleaver et al. 2004; DfES 2005; Kemshall et al. 2005; SEU 2005), which have shown that routine sharing of personal information is patchy at best, and continues to be so, despite the large number of government initiatives in this field. However, there has, hitherto, been no attempt systematically to map, compare or explain the variety of settlements that are actually struck in local services between competing imperatives for sharing and for protecting confidentiality. The research reported in this article was designed to fill this gap. It presents data from a major new study of local, multi-agency working in twelve cases of local multi-agency arrangements (MAAs) currently prescribed by legislation or national policy in England (8 cases) and Scotland (4 cases). These MAAs were drawn from four policy sectors, as follows:

- Integrated health and social care (H/SC)for elderly people

Integrated health and social care (H/SC) for mentally-ill people

- Local crime reduction and disorder partnerships (CDRPs) set up between local authorities, police, health and other agencies to reduce crime and criminality in localities 
- Multi-agency public protection arrangements (MAPPAs) set up between prisons, probation and police services, and other local agencies such as health and housing departments, to manage risks associated with violent or sex offenders living in local communities.

These sectors were selected because they are ones where street level bureaucrats and their managers must trade off various kinds of risk in deciding whether or not to share sensitive client information between agencies. These risks include risk of physical and mental harm to the client, or to their families or potential victims, risk of stigmatisation, risk of unwarranted incursions into the client's privacy, and risk of blame to the worker if matters go wrong. By definition, decisions about whether to share information necessarily take place under conditions where any one agency has much less information than it would ideally like about the scale of such risks. Nevertheless, judgments made on an everyday basis in such fields as these determine the extent to which, and the ways in which, ‘joined-up government’ actually works.

Semi-structured interviews were conducted between November 2003 and January 2005 with a total of 207 managers, professionals and information systems managers in 77 front-line agencies in these twelve MAAs. The size of this sample means that this is probably the largest empirical investigation of local data sharing practices yet undertaken, and the only one of which we are aware to investigate data-sharing and confidentiality practices in different policy sectors.

\section{Theory}

Previous studies cited above show that there is significant variation in the patterns of sharing exhibited within policy sectors. Accordingly, one could not expect to be able to explain all observed variation by reference simply to differences in function or sector. Thus, we did not expect to 
confirm such statements as "crime-related MAAs share more data while health-related ones share only referrals with consent". Nor do simple geographical differences appear to explain within-type variation, although, as we show below, jurisdictional differences between England and Scotland are proxies for important institutional factors. For the purposes of this research, we were therefore interested in exploring how social dynamics in different institutional contexts might explain variations in behaviour not only between different kinds of multi-agency arrangements, but also within and between ones of the same functional type. Given strong, current policy imperatives towards partnership working, we also wanted to develop a theory capable of distinguishing between institutional pressures for and against data sharing emanating from within an agency, and those emanating additionally from partnership arrangements prescribed by national government. We also sought to develop theory capable of recognising that institutions can act not only as constraints on, but also as spurs to, action, and that would thereby explain patterns of sharing as well as nonsharing.

In a recent paper (6 et al. 2004), we showed how a set of hypotheses about styles of data sharing could be derived from the neo-Durkheimian institutional theoretic tradition, in order to predict what data would be shared, or not shared, in the context of particular institutional forms. That tradition emphasises two key dimensions of social institutions - the degrees of social regulation and of social integration (Durkheim 1951 [1897]; 1961 [1925]). In this context, 'social regulation' assesses the degree of tightness with which institutions control and sanction behaviour, both formally, by means of rules, laws, authorisations, procedures and role differentiation, and informally through conventions, the setting of expectations, informal supervision and staff interaction. 'Social integration' assesses the degree to which individuals are institutionally bound by, and accountable to, a bounded group or collectivity. Cross-tabulating these two dimensions yields four distinct institutional forms which can be discerned in social life at every scale and in every human society; 
hierarchy (strong regulation and integration), individualism (weak regulation and integration), enclave (weak regulation, strong integration) and isolate (strong regulation, weak integration) (6 2004; 6 et al. 2002, 2006; Douglas 1982a [1978], 1982b, 1992, 1996; Gross and Rayner 1986; Hood 1998; Maesschalk 2004; Mars 1982; Peck and 6 2006; Rayner 1992; Thompson et al. 1990, 1999). The theory enables us to predict that distinct styles both of information sharing and of absence of sharing will emerge under each of these forms. Because many institutions exhibit hybrid institutional characteristics, the styles by which they share or do not share clients' information are expected similarly to represent combinations of two, three or even four of the features associated with the elementary forms.

Under hierarchical institutions, life is rule-bound, roles are clearly distinguished, membership boundaries are clear, and decisions are made under known systems of authorisation: power varies with status. By contrast, under individualistic institutions, people can exercise significant discretion to broker their way to access to resources, and can then use those resources to circumvent rules: status varies with power. In enclaves, collective action is sustained neither by power nor status but by shared commitment to whatever values or principles define the club or clan: boundaries between members and non-members, and between true believers and others, have to be heavily marked in order to sustain the enclave. Finally, in the absence of status, power or commitment in isolate forms, collective action is undermined, and people must adopt short-term coping strategies. Each of the basic situations emerges as people react with disappointment or surprise to the problems thrown up by each of the others (Thompson et al. 1990). The present argument is that in each situation, distinct practices of information-sharing and non-sharing will emerge. Sharing of clients' personal information or its absence will be, respectively, a matter of regulatory compliance (hierarchy), of instrumental and strategic calculation (individualism), of principled crusade (enclave), or of day-to- 
day getting by (isolate). Table 1 below summarises the styles of information sharing that are predicted for each institutional form.

\section{[table 1 about here]}

Because this research was primarily concerned with explaining variations in inter-agency datasharing practices among front-line staff, we focus in this article on the strength of social regulation and social integration apparent at the level of the organisations, agencies and teams which constitute the MAA, and which are actually responsible for substantive service delivery in these fields. We hereafter refer to all these constituent entities in membership of an MAA as 'agencies': they are listed in table 2 below. We were particularly interested in how degree of regulation and integration affects the data sharing practices of agencies' staffs. We focus on the two most important sources of regulation and integration: those sustained by the agency itself, and those imposed externally as a result of its membership of the MAA. Both sources of social regulation and social integration were explored systematically in interviews. Interviews also probed the ways in which institutional context promotes or undermines confidence of frontline staff that agencies in the MAA are sharing or not sharing data and respecting confidentiality 'appropriately'. This line of questioning was important, partly because a high level of anxiety about the appropriateness of data sharing or confidentiality arrangements was taken as a prima facie indicator of dysfunctional data sharing or confidentiality practices, to be explored by detailed analysis of transcripts. However, the more significant reason derives from national policymakers' assumption that the key to increasing the volume of data sharing lies in promoting local confidence in the recognition and management of associated risks to confidentiality. It was therefore thought to be especially important to understand the institutional contexts associated with different levels of confidence in both data sharing and confidentiality 
arrangements. We also focused our investigation into what people in agencies and MAAs would count as "appropriate" practice in relation to the sharing or non-sharing of data in each context. Specifically, we asked our respondents questions to elicit the considerations that they regarded as warranting sharing or not sharing. These might stress the importance of formal rules, the role of discretion in interpreting those rules, conceptions of purpose, the public interest, service management or information technology management issues. Secondly, we explored the converse of these conceptions of warrant - namely, greater and less tolerance of false positive and false negative judgment errors made when professionals assess whether or not the risks would warrant sharing of information. Finally, we examined how these differing and even rival conceptions of warrant and tolerance of errors were related to different patterns of formal and informal institutions within the agencies and at MAA level.

Thus, in relation to data sharing and confidentiality practices in frontline agencies, neoDurkheimian theory gives rise to the following hypotheses:

$\mathrm{H}_{1}$. Staff in agencies that are markedly hierarchical will exhibit high confidence that they are conforming appropriately to rules, national legislation and executive guidance laid down by the agency and/or by the MAA. This is because hierarchical forms foster reliance upon the rule-bound character of their processes and sense of clear agency boundaries, combined with structured means of inter-agency sharing,

$\mathrm{H}_{2}$. Staff working in settings marked significantly by isolate institutional forms will show lower confidence in the information sharing and the confidentiality practices of both their agency and MAAs than others; this is because individuals working in such setting will distance themselves from the institutional settings in which they are employed, and to show qualified loyalty to their practices. 
$\mathrm{H}_{3}$. Enclaves will show more confidence in their own practices than in those of the rest of their agency or MAA: this is because staff in enclaves will mark the boundary between their internal practices, and the values on which they are based, by showing greater confidence than in those of other agencies in the MAA. This ambivalence will appear in moderate confidence.

$\mathrm{H}_{4}$. Agencies and MAAs characterised by individualistic institutions will display moderate confidence. This is because individualistic institutions cultivate both a combination of wary vigilance but also willingness to seize strategic opportunities offered by gaps in regulation and integration offered by the agencies and/or the MAA.

To test these predictions, we collected and analysed two kinds of evidence, structured and unstructured. The structured evidence takes the form of data gained from interviews designed to assess the institutional forms exhibited by the agencies in the study. Secondly, we present unstructured, qualitative evidence in the form of quotations taken from line-by-line analysis of all the interview transcripts designed to explore whether (a) the styles of sharing and non-sharing and (b) the levels of confidence predicted by the theory are, indeed, associated with institutional form.

\section{Institutional variables}

The first analysis therefore shows the institutional forms of the constituent agencies of the twelve MAAs. To make clear the distinction between social regulation and social integration emanating from within the agency and externally from the MAA, we report two distinct institutional form codes for each agency in the study. ${ }^{2}$ The first, entitled "agency by $M A A$ ", shows the institutional form resulting from the degree of regulation imposed externally on the agency explicitly as a result of its membership of the MAA - that is from rules or guidelines issued by the MAA or by national 
guidelines to which the MAA is obliged to adhere - and the extent to which the agency is integrated with the rest of the MAA. Thus, an agency in which its staff were subject to a high level of effective regulation as a consequence of membership of the MAA, but which appeared in practice not to be well integrated into it, would be judged to exhibit isolate characteristics so far as its 'agency by $M A A$ ' coding was concerned. The second code, entitled "agency by agency", shows the institutional forms resulting from the degree to which the agency's staff are subject to internally-generated regulation and to which they are integrated into their own agency. Thus, if the same agency were strongly integrated internally, and was also able to rely strongly on established rules, authority or accepted conventions to regulate its members, it would deemed to be strongly hierarchical on the 'agency by agency' coding. Hybrid institutional forms are shown in the order of greater pre-eminence: thus H/E signifies a hybrid form dominated by hierarchy but with some enclaving. The institutional forms displayed in these columns were built up from a complex set of codes reflecting a variety of indicators of regulation and integration. Thus, we used a "top down" method of qualitative analysis in which codes derived from theory are pre-defined for the purpose of analysing transcripts. This contrasts, for example, with "bottom up" open-coding methods of analysis, such as those associated with grounded theory.

[table 2 about bere]

Most agencies exhibit hybridity in institutional forms, as the theory predicts (e.g., Thompson et al. 1990, 86). However, the majority show a clustering along the positive diagonal in table 1 from hierarchy to individualism. 
As we might expect, there are indeed agencies where the "agency by $M A A$ " score shows greater regulation than the "agency by agency" score, but not necessarily greater integration. Indeed, there are agencies which are internally strongly integrated and appear thereby to be precluded from being well-integrated in the MAA. For example, "agency by $M A A$ " codes of housing departments, police services and fire services suggest that they have a tendency to be rather isolated within MAAs. This is especially the case, as the theory would predict, where agencies exhibit enclaved institutional forms, because enclaving heavily underscores social boundaries. Other agencies appear less integrated internally, but are nevertheless more strongly integrated into the rest of the MAA: these are typically ones that have been specifically created as a result of the formation of the MAA. Examples are agencies set up specifically to offer data analysis services to the MAA (for example, agency 5C). In this article, we offer no explanations for this particular distribution of institutional forms (for this, see Bellamy et al. forthcoming). Rather, we focus here on the issue of central theoretical interest, namely the relationship between these institutional forms and patterns of data-sharing.

\section{Styles of information sharing}

It is clear that, with the exception of the Scottish crime reduction and public protection MAAs, the establishment of all the MAAs in the study was associated with attempts considerably to strengthen 'agency by $M A A$ ' regulation of partnership working, in general, and information management practices in particular. Nearly all the MAAs had developed extensive formal documentation on key aspects of their client information management. Most had local protocols on information sharing and many had also adopted local confidentiality or privacy policies, although many also reported problems in achieving sign-up by the full range of participating agencies. In some cases, this range was very extensive: for example, over fifty agencies are typically involved in multi-agency public protection arrangements (MAPPAs). In each case, the work of MAAs is governed by national codes 
specific to their field. In the case of the MAPPAs, national government has issued particularly detailed guidelines which have the force of legislation, as do those governing the working of H/SC agencies for both elderly people and the mentally-ill. Data sharing by English police services is prescribed by the Association of Chief Police Officers' Data Protection Code of Practice (2002) but does not have the force of law. In health and social care, a number of codes relating to data protection and confidentiality apply, including the National Health Service (NHS) (2003) Code of Confidentiality and those adopted by professional institutes such as the British Medical Association, the General Medical Council and the Royal College of Psychiatrists, which restrict data sharing about patients to purposes that are more narrowly defined than is required by the CDRPs and MAPPAs. Broadly similar documents have been approved for use in Scotland, which has separate arrangements for crime reduction and public protection that rely on local voluntary action rather than national legislation to establish partnership working. Even those Scottish MAAs that exist as a result of local choice produce written documents specifying their powers, roles and purposes. It is therefore unsurprising that many of the agencies in the study show a bias for strong regulation in general and for hierarchical styles of organisation in particular.

In none of the MAAs was the handling of client records conducted entirely electronically at the time of the interviews, and access authorisation rules to client data on those electronic systems that did exist varied significantly, even between the pairs of English cases within each of the four sectors. Some agencies routinely allow accredited staff access to the whole database while others permitted access only to specific case records, or shared information from them verbally, on a need-to-know basis. In general, mental health bodies permitted access for accredited mental health professionals on a trusted basis to sensitive information in individual records, but were reluctant to grant routine access to whole databases to any agency outside the health service and/or dedicated mental health teams. Information on the scope of access shows that, in general - as we should expect, given the 
longstanding character of both professional and the recent character of national regulation in the health service - it is healthcare and related agencies that segment access within the individual record to the greatest degree, defining "need to know" not only by role but by health episode or event. This may reflect the much greater integration of multi-professional teams within the same agencies in the mental health MAAs and the tendency to intensive team casework in that field. By contrast, agencies were more inclined to share to share structured data more routinely for the purpose of crime analysis, albeit in (sometimes weakly) anonymised form. By contrast, the MAPPAs assume case-bycase access to case documents, and a new national database of sex offenders, ViSOR, will soon provide access to a single case file and risk assessment to the three core responsible agencies; police, prisons and probation service. However, there is nothing purely functional about the nature of the clientele or the fact of working in a particular field itself that requires these practices: they are, as we shall show, contingent effects of the institutional character of the agencies and MAAs.

Table 3 summarises the key differences between agencies in respect of the character and subjects of their client record systems and type of access rules.

\section{[table 3 about here]}

\section{Confidence that information is shared appropriately and confidentiality respected}

We now turn to the extent to which frontline practitioners are confident about data sharing and confidentiality practices in their agencies and MAAs.

In a study that used interviews rather than (for example) participant observation or detailed analysis of actual case records, ${ }^{3}$ it is necessary to rely heavily on the self-assessment of interviewees, and in any case, for reasons explored above, we were interested in exploring how interviewees' framing of the issues differed from each other, and how this was linked with institutional context. 
We encouraged our interviewees to be candid about their practices and their attitude to them, assuring them of confidentiality of both their own identities and of their agencies. We decided to allow them to give us their assessment in their own words in a semi-structured interview, because we saw no meaningful way of offering the interviewees closed questions or rankings.

The rankings displayed in table 2 are therefore constructed from codes designed systematically to assess how confident the interviewees in each agency were, on average, that their agency was sharing information of the right kind in those cases when they felt it ought to, and that it was respecting confidentiality when it ought to. This is a measure of interest for two reasons. Firstly, when it takes a low value, it may indeed indicate the presence of some practices or absence of others that gives cause for disquiet. High values cannot be interpreted so straightforwardly, even as rough proxies for appropriate sharing and conformity with standards of confidentiality, for clearly people are able to persuade themselves that they are performing well or to represent themselves as doing so even when this is not the case. However, positive claims have been associated with other variables in the data set in ways that are illuminating in their own right. If greater confidence in information management practices is distributed in systematically uneven ways, this may help us to understand the factors that cause people to be reassured or uneasy, whether this confidence or lack of it is objectively well-founded or not. There were differences of view among the interviewees in almost every agency, which means that, almost unavoidably, the resulting scores, which are averages, tend to converge on either side of moderate confidence. ${ }^{4}$

\section{Explaining confidence in sharing and confidentiality}

In general, it seems clear that agencies in the six MAAs working in H/SC show higher levels of interviewee confidence in the appropriateness of sharing and of confidentiality practice in their MAAs than do those in agencies involved in CRDPs or MAPPAs. The highest level of confidence is 
shown among interviewees in the MAAs coordinating H/SC for older people, and weakest level of confidence in the CDRPs where internal conflict among the police about the appropriateness of sharing with other agencies is particularly marked. This conflict reflects wider tensions between the deep-seated institutionalised preference of many police officers for crime fighting, which emphasises security of police intelligence, and the more recent emphasis on intelligence-led crime prevention, which is more sympathetic to inter-agency sharing (Tilley 2003).

There are few agencies that exhibit significant divergence in the degree of average interviewee confidence in data sharing and in confidentiality practices, but there are some contrasts between England and Scotland that may reflect differences in the legislative and regulatory framework of partnership working in the two countries. For example, in the crime-related partnerships in England, police interviewees frequently claim that the Crime and Disorder Act 1998 overrides data protection legislation, though this is by no means accepted by other agencies within the MAA, particularly by those in health. Nevertheless, English police officers often report that they use this Act as legal cover for a variety of informal practices in securing information. By contrast, Scottish police interviewees, who are not covered by the Act, seem much less willing to engage in data exchange. Perhaps because of the absence of this legislation in Scotland, the Scottish police do not draw nearly such a sharp distinction between information required for crime fighting and for crime reduction functions. Some Scottish interviewees suggest that one inhibitor of information sharing with the police concerns the possibility that the information shared might be counted as a "statement to" the police: conversely, one police service in Scotland told us that they were willing to resort to compelling sharing by other agencies in the MAA, on the grounds that withholding information amounts to the offence of obstructing the police in the course of their inquiries.

The richest picture when the relationship between institutional form and the styles of information sharing are explored. Clearly, the overall bias of the sample is toward hierarchy. 
Consistently with this bias, we should expect, that information-sharing practices and confidentiality practices will generally tend to be strongly regulated, especially by agencies within the MAAs, as well as by the MAAs.

The question then is whether the data tends to confirm the hypotheses presented above. As $\mathrm{H}_{1}$ predicts, hierarchy appears to be associated with higher confidence in information-sharing practices within agencies. All but one of the seven purely hierarchical agencies also register as high or medium-to-high on satisfaction with information sharing, and so, too, do eleven of the twenty hybrids in which hierarchy is an important element. Only one hybrid with a significant element of hierarchy registers low on this measure. By contrast, as $\mathrm{H}_{2}$ predicts, none of the purely isolated agencies exhibits high confidence in the appropriateness of their information-sharing practices. It is important to recall that that the actual practices in hierarchical institutional settings may not be objectively better than those of the others, but a strong sense of compliance with rules and stronger integration may provide staff with a "comfort blanket" for making what may sometimes be very difficult and personally risky judgments. For this reason, strongly hierarchical institutions may be associated with higher volumes of data sharing.

When satisfaction with confidentiality practices is examined, however, a more complex picture emerges. In general, agencies generally show higher confidence in their confidentiality than in their data sharing practices, and this effect is more heavily marked - just as $\mathrm{H}_{3}$ predicts - as the articulation of enclaved institutions increases - that is, especially in the mental health cases. Staff in five of the agencies with purely hierarchical forms report high or moderate-to-high confidence, along with eleven hybrids with significant hierarchical elements, though different ones from those which show strong confidence in their information sharing practices. Only eight of the 22 agencies coded as having hybrid institutional forms with a significant isolate element register high satisfaction with their confidentiality practices, and only seven of the eighteen agencies with pure or hybrid 
enclaved forms do so. Consistently with their slightly greater tendency to exhibit hierarchy, agencies in the health/social care MAAs generally report stronger confidence in their sharing practices than do those in CRDPs and MAPPAs. Indeed, those in CDRPs, which are the most likely to exhibit significant individualism, report lower levels of confidence in the appropriateness of their sharing and confidentiality practices, which is what $\mathrm{H}_{4}$ predicts.

It can be seen, then, that the evidence tends to confirm the hypothesis that styles of sharing are shaped by institutional form, and that governmental attempts to induce more confidence in managing associated risks to confidentiality are also mediated by institutional form. The codes presented in table 2 are, however, abstractions from, and therefore inevitably reduce, the rich insights available from what is, after all, a detailed and extensive qualitative dataset. In the following sections, we therefore provide different kind of evidence, in the form of quotations from interview transcripts, by way of illustrating some of the ways in which institutional contexts shape the ways in which frontline staff and their managers frame and perceive themselves to manage the apparent tensions between data sharing and confidentiality.

\section{Institutional forms and styles of information sharing}

To simplify the analysis, we focus on agencies that exhibit less hybridity, because the associations predicted in table 1 are clearer in these cases, and because the agencies that exhibit hybridity in their basic institutional forms also show hybridity in their information-sharing practices.

\section{Enclave}

The articulation of enclaved elements within the institutional mix is predicted to be associated with patterns of information sharing that strongly differentiate the in-group within which sharing will be 
regarded as necessary and acceptable and others with whom it will be regarded with suspicion. Consistently with the hypothesis, the mental health case studies, where enclaved elements are most clearly marked, show the greatest tendency to emphasise sharing of client information within the specialist team (assertive outreach, crisis resolution etc), and a distinct tendency not to trust other agencies within the wider MAA. For example, a manager of a psychiatry team which constituted one of the agencies in MAA 1 (H/SC for mental health) commented that

... I guess I would see myself as belonging to would be firstly the team and then probably under the locality and then the Trust and probably the kinda wider bit of you know the LITs and the PCT

The manager of another psychiatry team also stressed the internally focused, internally egalitarian, principled character of the decision-making procedure adopted with respect to sharing of client information beyond the team:

Whatever comes to information sharing, it is again the team that talks about it, we have to weigh the risks, the advantages, you know the whole works.

The overall tendency of enclaving is to inhibit information sharing across the MAA and to make a fetish of confidentiality as a way of policing the boundaries of the team. A manager of the an Early Intervention in Psychosis team in the same MAA describes well the sense of distance between this agency and the rest of the MAA: 
I've been in [names $M A A]$ for twenty five months now and I guess ... I don't have a buge amount of input with it]. I don't actually have an awful lot to do with it, although I know I try and influence it to make sure Intervention is a priority.

By contrast, boundaries in such enclaves are often drawn to include certain categories of clients particularly identified with the enclave. A worker in an Emergency Psychiatric Team, which often has to deal with mentally ill people in a confused, distressed and, sometimes, dangerous state, complains of the unwillingness of another agency in this MAA - a team working with people who misuse drugs and alcohol - to share information about their clients so that risk to staff could be accurately assessed :

Well because of the nature of their work, they've got ... very strict confidentiality rules between themselves and their clients. And unless the client has got a written statement with us here authorising us to get information from drug and alcohol team they just wouldn't give us any information

A manager of an assertive outreach team, also in MAA 1, talked of their dedication to their clients and to the protection of their personal information. He therefore objected to the use of generic consent forms to share information with other agencies. This sense of commitment to confidentiality on the basis of principle rather than to the letter of regulatory prescription is particularly important in enclaved settings:

But, you see, signing a form that gives permission to share information with other agencies is like signing a blank cheque. Each case is different and if I was a patient I wouldn't 
sign any such form, I would be saying "well what information do you want me to share and with whom". So when, when it's required it should be discussed with the client, it's no good saying you've got a letter of consent in the file to share information and then share it with everyone else. That's not good, that's not clear in respect of confidentiality.

Enclaved institutional forms are particularly common throughout our dataset in teams that are on the margins of MAAs, and they tend both to result from and to reinforce distrust. A community psychiatric nurse in MAA 8 (a MAPPA) told us:

I think the information that we share as a team is absolutely fine and I'm kind of comfortable with the fact that everybody is working under their proper terms and conditions to secure information. But it's the amount of people that have got access to information now that don't abide by these rules necessarily worries me...

It would stop me from sharing information, yes it would, unless it was going to put a person in danger. [...] And I might say to somebody 'I don't think you should be going in there" and if they said to me "Why not?" I would say "I don't know that I want to discuss that with you but I'm telling you, with the information I've got, you shouldn't go in there".

... But I think it's realistic paranoia in the fact that there is so much... so many peripheral people working in teams now, and where do you stop with that information, or bow do you then include these people in ... confidentiality. But, you know, you're still only working on people's say so, so it's difficult. 
Conversely, MAA level staff in more hierarchical settings can be frustrated by the preciousness of enclaves about confidentiality, their excessive confidence in their internal information handling practices and their unwillingness to integrate with others in the MAA:

I don't like the idea of teams having their own little confidentiality sort of thing, you know. We need to be mindful of confidentiality, and we need to be sharing information with other people within a fair framework of risk and we need to be mindful of people's confidentiality because it can break down. People can get free and easy

As we should expect in a setting with a marked articulation of enclaved institutions within an overall mix that does include a significant hierarchical element, the forms of regulation of information sharing and confidentiality that are stressed as most acceptable are those which are based in professional codes, rather than those which flow from the agency or the MAA. This manager of an early intervention in psychosis team is quite typical in the assertion of collectivelyespoused principle as more authoritative than organisational prescription:

I'm pretty sure again I guess I take my confidentiality from my own, I think there are trust guidelines but I can't remember or even flicked through them, but I would bave a very good idea of what was confidential and it would be ... from my professional organisation and professional training which is about things can be broken only if you think people are at risk otherwise everything is confidential. 


\section{Individualism}

In institutional settings exhibiting a greater degree of individualism, albeit in settlement with hierarchical and other elements, we expect data sharing to be subject to individual discretion or negotiation. Individualistic institutions allow greater scope for disagreement between individuals, and for differing interpretations of the same practices. So in settings in which individualism is combined with hierarchy, we should also expect the emergence of conflict over information sharing between formally sanctioned authorities and people in subaltern roles. We should also expect to find a more instrumental attitude to sharing and confidentiality than the principled tenor of discussion in settings where enclaving is found to a significant degree.

This is clearly borne out in MAA 5, a CDRP which included two managers vigorously engaged in individualistic behaviour that ran counter to the information-sharing practices of their agencies. When asked about their approach to information sharing, a police superintendent talked of their role in influencing the employment of street wardens by the local authority to tackle anti-social behaviour. They justified blocking one individual in the following way:

And that individual had been arrested for murder, and ...I think was charged and acquitted, but there were very real concerns about the person's character and there were the sort of things that they needed to know but ... I've influenced that person's employment and ... again you're back to, does the end justify the means, and I dare say a barrister could earn a few pounds out of $[X X X]$ Police for that particular case, but what do you do, you know do you then ... have somebody who has a fetish for martial arts become a street warden to go out and tackle anti social behaviour, I think (laughs) it would be madness. 
This focus on instrumental action is based on cutting deals with colleagues and in playing the role of broker or kingpin between different groups, by securing near-proprietary personal control of expertise:

Now the information sharing there [with local authority housing and Sure Start] is fantastic, because if you want any information you just walk next door and ask and it's done, and it's done because they share the same canteen, they share the same changing facilities, you know what I mean, it is one body that actually work together, so if you ask them what the protocols are, I suppose you ask me cos I'm responsible for them, the answer is there aren't any, they just do it, they work together on a day to day basis because they're all dealing with the same problems, and assisting each other in tackling their problems

Even in strongly-integrated institutional settings, we have evidence of some individualistic behaviour amongst people who believe that their personal effectiveness depends on behaviour at odds with a dominant culture. This is most marked in our sample amongst policemen whose resultsoriented training sometimes grates against the preoccupation of social care and health professionals with clients' rights. It is here that we found some of the clearest expressions of the clash between a dominant individualist conception of confidentiality, that wants to privilege the immediate rights of known individuals and a utilitarian framing of information sharing that wants to privilege the interests of the wider public, however remote the risk. Here, for example, is another senior policeman, the joint chair of the MAPPA (MAA 7), asserting that, in a field devoted to protecting the public against particularly repugnant crimes, the free sharing of almost all personal data can be justified. This is an opinion that he knows not to shared by other leading players in this MAA, but 
for this person, there is a straight choice between information sharing and confidentiality, and he is sure he knows how to make it:

I would say that any snippet of information from whatever source could prove to be crucial in the management of a sex offender. Now at the end of the day, I appreciate there have got to be safeguards which are built into that and the safeguards of the human rights act etc. But you've got to look at the duty of care we have as a statutory agency in terms of the management of the whole issue around public protection.

As one would expect, then, the presence of conflict is associated in this MAA with markedly lower confidence that the decisions taken about sharing and confidentiality are generally appropriate.

\section{Isolate}

In institutional settings in which isolate ordering plays a significant part, we expect information sharing to be opportunistic, a matter of day-to-day coping behaviour rather than the principled decision emphasised in enclaves or the instrumental calculation in individualistic institutions. In isolate settings, we can expect trust between agencies and professions to be relatively weak. Isolate ordering is significantly more marked in MAA 6 (a CDRP) than in most of the others. As predicted, there is limited trust between agencies in this MAA and markedly lower confidence that both sharing and confidentiality decisions conform to norms prescribed by the hierarchical elements within this MAA's institutional mix. People in isolate settings find various ways of distancing themselves from the form of social regulation under which they operate; they conform to it both without enthusiasm and without strategy. For example, discussing the practices of a local authority directorate, a manager describes how they view sharing as fulfilling the agency's objectives, even though it risks 
overriding professional principles. But - so distant is the manager even from professional codes, let alone from agency ones - that they describe "riding roughshod" over clients' rights as a "technical" matter:

Within the organisation I accept it, I signed up objectives of the organisation and the guidance issued by Government. I actually think it, I think it's, it runs the risk of being excessive, the amount of information we're sharing and, and in a sense you're technically in danger of riding roughshod over individuals' rights.

Conversely, interviewees from agencies displaying significant isolate elements in their institutional mix were more likely than any other set of interviewees to be critical of their own information-sharing or confidentiality practices, or of those of their agencies. This is partly a function of their moral and psychological dissociation from the agency in which they work. But it sometimes allows the exercise of independent moral reasoning, albeit moral reasoning which never quite connects with decision processes in the wider MAA. Some workers simply do the best they can on a case-by-case basis, knowing that matters are far from right, but with no great confidence that they will improve. Here, for example, is a professional worker in team concerned with drug and alcohol misuse in one of the CDRPs, talking about the inappropriate constraints imposed by confidentiality rules on their ability to work in a multi-agency setting, but apparently accepting them in a fatalistic manner:

No, I think we, we all understand the constraints under which we've got to... I can't issue crime, I can't issue police officers with bealth data, I can't issue Health crime data, and we just have to, to play in that way. 
Behaviour inspired by isolate institutions frustrates people working within other institutional forms. A strong theme across our data set is the invocation of data-protection legislation or professional confidentiality norms - sometimes arguably incorrectly in law - to insulate professional workers from the risks associated with exercising professional responsibility by sharing data, even where it may have been thought appropriate to do so. For example, in case study 8, a MAPPA, which is, overall, a strongly hierarchical institution, we found several agencies complaining about psychiatrists who are unwilling to resolve dilemmas presented by patient confidentiality, on the one hand, and the risks posed by mentally ill people, on the other. Here is a senior manager in an agency charged with managing and delivering primary health care for mentally-ill people:

...there was certainly one occasion where it had been reported that an individual was extremely dangerous and should not be seen, no-one should see the person on their own. That was reported as being a comment from the psychiatrist who had been looking after this guy, but we couldn't get a psychiatrist to actually say that. Couldn't actually get bim to put that into a report or to provide any advice to us. And that is frustrating, and that was frustrating. And I think he sort of held, he bid bebind the patient confidentiality.

\section{Hierarchy}

In hierarchical settings, we expect sharing and confidentiality practices to be matters of rulefollowing, and conformity with norms to be those of professional and, especially, organisational status and responsibility. The two sets of MAAs that most frequently exhibit hierarchy in a pure form are the the English MAAs charged with delivering integrated H/SC services for older people and the MAPPAs. Both sets of MAAs were formed as a result of new, national programmes and 
both programmes are subject to detailed national government prescription of informationmanagement practices and systems. Both sets in our sample have one MAA which was selected to pilot a new national initiative because partnership working in it was considered to be well established.

Our analysis confirms, overall, that that, as predicted by theory, an element of $\mathrm{H}$ in the institutional mix tends to increase confidence that data are being shared appropriately, and that confidentiality is being properly respected. This confidence does not rely only upon formal rules, but also upon the informal ones associated, for example, with shared professional experience and standards. We should not assume, however, that this confidence is necessarily warranted by independent judgment, or still less that the settlements struck in hierarchical settings are necessarily optimal. It might be that strong regulation and strong integration encourage complacency, or that they afford scope for cognitive dissonance-reduction leading to over-statements of confidence in interviews. We found rather less grumbling by interviewees about the inhibiting effect of laws, rules and codes than we expected, but this does not mean that formal regulation never deforms decisionmaking in unintended ways. There is some evidence of both in institutional settings with a strong element of hierarchy.

The most obvious consequence of excessive regulation is that it relieves workers of personal responsibility for their decisions, and may push some into isolate responses. A worker in a team working with drug and alcohol abusers in MAA 5 told us, when asked if they were more worried about being blamed for sharing or not sharing data:

From a personal side, as long as I could justify to myself that I'd followed due process .... I think from a personal side it really wouldn't matter to me. 
A less obvious, but in many ways more important, source of deformation associated with hierarchical settings, stems from the fact that formal regulation can never be complete. It may well deliver less certainty and security than the prevailing informal institutions demand. Workers are forced into the unanticipated exercise of personal judgment, which they may seek to avoid, giving rise to confusion and to demands for yet stronger regulation. The same interviewee continues:

But I think the legislation around that whole issue of information sharing is so complex that people have no clarity about what they can and cannot share um and in terms of managing risk or trying to work together as a $M A P P A \ldots$ that can cause complications for us, so I think if there was one theme that ran through it for me, is that it would be much more beneficial if the ability to share information was made much more clear and was enshrined in legislation.

The perception of contradiction between different sources of regulation can appear to some people to allow dangerously high levels of discretion. Here is a Superintendent of Police speaking about the Crime and Disorder Act 1998, which established a legal mandate for information sharing to prevent or detect crime and which, he claimed, liberates him from other controls governing confidentiality in the MAA:

... the Crime and Disorder Act, and I can't quote the section, but there is a particular section around, really runs a train right through data protection because it says, well you know if it's in the interests of preventing crime and disorder and it's a responsible body that you're giving it to, then go ahead and give it and that's ... the permission that we 
take to do it. In terms of best practice we're not there yet because we don't have a protocol which covers everything that we actually share.

Notwithstanding such demands, the proliferation of codes and rules intended to provide more clarity, may exacerbate problems if they add regulation without adding coherence or understanding. The following quotation from an interview with a manager of a psychiatric day centre in MAA 2 illustrates this problem well:

Well I mean, the thing is, I'll refer to psychological guidelines by the association, I would refer to social work, guidelines. I'll refer to nursing guidelines .... We have got guidelines but we haven't got a policy.

As we conducted this research, we therefore became increasingly convinced that the imposition of formal rules, however detailed and prescriptive, is at best an incomplete response to the problem of achieving appropriate settlements between information sharing and privacy. Just as in military settings, where, as Field Marshall von Moltke is supposed to have said, no battle plan ever survives contact with the enemy, so in the governance of professional services, no set of protocols or rules exactly prescribes choices when frontline workers are faced with particular practical dilemmas and necessarily leaves scope for judgment about the circumstances in which the rules apply. Indeed, the imposition of additional formal regulation may sometimes increase, rather than reduce, hesitancy, unpredictability and inconsistency. It may reinforce unrealistic expectations of certainty, causing staff to become averse to taking decisions containing even a small degree of risk, even where they are sanctioned by policy. And in situations where formal regulation is contradictory or where it runs counter to informal conventions, it may augment space for untrammelled discretion. 
This brief exploration of the detailed material in the interview transcripts serves to illustrate the general point that aggregate institutional mix within each agency in the set constituting an MAA is not by itself a sufficient explanation of the degree of interviewee confidence in its information management practices. Analysis of the coding of agencies show that increased hierarchy, in the form of additional formal regulation, especially in the 'agency by $M A A$ ' codes, appears to be associated with assuming MAA status in policy fields characterised by a high degree of central prescription, and this is particularly so in the fields, such as the MAPPAs and H/SC for older people. Agencies in these MAAs also show relatively high interviewee confidence in data sharing and confidentiality. The presence in these cases of MAAs selected to pilot new national initiatives suggests, however, that we may be picking up a Hawthorne effect associated with being under close scrutiny by government. Certainly, the discussion above suggests that it may be wrong to conclude from this data that "hierarchy works" to govern decisions and to cultivate confidence that the spirit of regulation is being followed. Rather, the relationship between hierarchy and satisfaction is a complex one, and itis important to attend to the social dymanics of agencies, as well as their interaction with each other in the MAA, in order fully to understand the underlying forces.

\section{Conclusion}

This study has explored empirically the power of the neo-Durkheimian institutional theoretical tradition to shed light on local information-sharing practices, by developing and operationalising a theoretical framework capable of identifying and explaining patterns of information styles in over 70 agencies involved in nationally-prescribed multi-agency arrangements in England and Scotland. These agencies all work in fields where the sharing of sensitive personal information is increasingly prescribed by law and other formal policy instruments. We have shown that distinct styles of handling personal information can be discerned, and that they can be explained by their consistency 
with the deeper institutional character of the organisational settings in which they are found. In particular, the emergence of hierarchical institutional settings (or hybrid forms in which hierarchy is prominent), and the influence of this form on the ways that staff in these agencies attempt to strike settlements between confidentiality and privacy, is seen to be entirely intelligible. We conclude that the combination of direct and indirect evidence presented here tends to confirm the neoDurkheimian theory that there is a limited diversity of styles of sharing and non-sharing of client information, and it is the particular institutions of social regulation and social integration that are key in explaining why a particular agency or exhibits the style that it does, in the context of partnership working

This work is important methodologically because it is able to report progress in operationalising two important dimensions of neo-Durkheimian analysis, for the purpose of conducting empirical research. First, it has developed and made use of a technique for assessing and displaying hybrid institutional forms, as well as pure institutional forms, thus increasing the granularity of the resulting analysis. Second, it has addressed an important methodological challenge for operationalising neoDurkheimian institutional theory (Mamadouh 1999), by collecting and analysing data relating to complex organisational arrangements in which the relevant variables operate and interact at multiple levels, namely at agency level and at partnership level, and also in ways that are shaped by national policy. This article has focused on practices at the front line of service delivery agencies, but in so doing has particularly distinguished the independent effects of institutional features emanating from additional regulation of information sharing accruing from partnership working and top-down prescription.

The resulting findings are of policy as well as of theoretical significance. The theory implies that when institutional forms change, practices will change: the question then is how easily institutional forms can be changed by explicit policy intervention. The research presented in this article suggests 
that the imposition of top-down regulation does result in the addition of regulation, but not of social integration, in the institutional mix: MAAs, and agencies that compose them, can therefore be expected to change in their institutional forms over time. However, the present research presents snapshot data of agencies and MAAs: longitudinal data are not yet available to explore exactly how they may do so. There is a significant body of work in the neo-Durkheimian tradition on modelling institutional change explained by endogenous processes of positive and negative feedback (e.g., 6 2003; Thompson 1982, 1992, 1996), which could be explored in future using such data as those presented here. It is clear, however, from these data that deliberately induced change, using policy instruments available through formal institutions alone, is possible but not straightforward. Indeed, the discussion presented here suggests that such instruments may even be counter productive if they further reinforce tendencies of frontline staff to cultivate isolate, enclave or individualist institutions by developing workarounds to national regulation. Moreover, as we show elsewhere (Bellamy et al. forthcoming), the factors that lead agencies to exhibit the range of institutional forms that they do are ones associated with such factors as the nature of the services provided, the nature of the partnerships at stake, the technological infrastructures available to partnerships, and the institutionalised professional practices that dominate these fields. Some of these factors have become relatively fixed, structural ones, and none is easily malleable. All this suggests that we should have limited expectations of the capacity of additional central government explicit regulation alone to discipline public services into adopting consistent practices and decision rules for information sharing. Increasing formal and explicit central regulation of information-sharing practices will not of itself sufficiently change the institutional degree of social regulation and social integration in frontline public services to ensure uniformity of practice and therefore equity of outcomes

\section{References}


6, Perri. 2003. Institutional viability: a neo-Durkheimian theory. Innovation: the European Journal of Social Science Research 16 (4): 395-415.

—, 2004. Joined-up government in the western world in comparative perspective: a preliminary literature review and exploration. Journal of Public Administration Research and Theory 14 (1): 103-138.

6, Perri, Christine A Bellamy, and Charles D Raab. 2004. Data sharing and confidentiality: spurs, barriers and theories. paper given at the Political Studies Association conference, University of Lincoln, 5-8.4.04. http://www.psa.ac.uk/2004/pps/6.pdf.

6, Perri, Nick Goodwin, Edward Peck, and Tim Freeman. 2006. Managing networks of twenty-first century organisations. Basingstoke: Palgrave Macmillan.

6, Perri, Charles D Raab, and Christine A Bellamy. 2005. Joined up government and privacy in the United Kingdom: managing tensions between data protection and social policy, Part I. Public Administration 83 (1): 111-133.

6, Perri, Kimberley Seltzer, Diana Leat, and Gerry Stoker. 2002. Towards holistic governance: the new agenda in government reform. Basingstoke: Palgrave Macmillan.

Association of Chief Police Officers. 2002. Code of practice for data protection. Association of Chief Police Officers, London. http://www.acpo.police.uk/asp/policies/policieslist.asp.

Baines, Sue, Pat Gannon-Leary, and Sarah Walsh. 2004. FrAMEwork for multi-agency environments: final report of the Learning and Evaluation strand. Newcastle: University of Newcastle.

Bellamy Christine A, Perri 6, and Charles D Raab. 2005a. Joined up government and privacy in the United Kingdom: managing tensions between data protection and social policy, Part II. Public Administration 83 (2): 393-415.

Bellamy CA, Charles D Raab and Perri 6. 2005c. Multi-agency working in British social policy: risk, information sharing and privacy. Information Polity, 10 (1-2): 51-63. 
Bellamy CA, Perri 6 and Charles D Raab. forthcoming. Information-sharing and confidentiality in social policy: regulating multi-agency working. Public Administration.

Bichard Inquiry. 2004. The Bichard Inquiry report. London: Home Office.

Cabinet Office, 2005, Transformational government: enabled by technology. Cm 6683. London: Cabinet Office.

Cabinet Office, 2006a, Terms of Reference of the Ministerial Committee on Data-Sharing (MISC 31), available at: http://www.cabinetoffice.gov.uk/secretariats/committees/misc31.asp

Cabinet Office, 2006b, Reacbing Out. Action Plan on Social Exclusion. London: Cabinet Office.

Cabinet Office, 2006c, Government information sharing can help protect the most disadvantaged. Press Release. London: Cabinet Office, 13 September 2006

Challis, Linda, Susan Fuller, Melanie Henwood, Rudolf Klein, William Plowden, Adrian Webb, Peter Whittingham and Gerald Wistow. 1988. Joint approaches to social policy: rationality and practice. Cambridge: Cambridge University Press.

Cleaver, Hedy, Daniel Cleaver, Deborah Cleaver, and Vanessa Woodhead. 2004. Information sharing and assessment: the progress of 'non-trailblazing authorities. London: Department for Education and Skills.

DCA (Department for Constitutional Affairs). 2003. Public sector data sharing: guidance on the law. London: Department of Constitutional Affairs.

DCA (Department for Constitutional Affairs). 2006, Information sharing vision statement. London: Department of Constitutional Affairs.

DfES (Department for Education and Skills). 2005. Learning from information sharing and assessment trailblazers. London: Department for Education and Skills.

Douglas, Mary. 1982a [1978]. Cultural bias. in In the active voice. Mary Douglas. 1982. 183-254. London: Routledge and Kegan Paul.

—, 1982b. Essays in the sociology of perception. London: Routledge and Kegan Paul.

—, 1986. How institutions think. London: Routledge and Kegan Paul.

_ - 1992. Risk and blame: essays in cultural theory. London: Routledge. 
—, 1996. Thought styles: critical essays on good taste. London: Sage.

Durkheim, Émile. 1951, [1897]. Suicide: a study in sociology. tr John A Spaulding and George Simpson, London: Routledge.

—, 1961 [1925]. Moral education: a study in the theory and application of the sociology of education. tr Everett K Wilson and Herman Schnurer, New York: Free Press.

Gross, Jonathan and Steve Rayner. 1986. Measuring culture: a paradigm for the analysis of social organisation. New York: Columbia University Press.

E-government Unit. 2005. Transformational government: enabled by technology. CM 6683. London: Egovernment Unit, Cabinet Office.

Hood, Christopher C. 1998. The art of the state: culture, rhetoric and public management, Oxford: Oxford University Press.

Kemshall, Hazel, Gill Mackenzie, Jason Woods, Roy Bailey, and Joe Yates, 2005. Strengthening MultiAgency Public Protection Agreements. London: Home Office.

Laming, Lord. 2003. The Victoria Climbie inquiry. London: Department of Health and Home Office. Maesschalk, Jeroen. 2004. The impact of new public management reforms on public servants' ethics: toward a theory. Public Administration 82 (2): 465-489.

Mamadouh, Virginie. 1999. Grid-group cultural theory: an introduction. Geojournal 47, 395-407.

Mars, Gerald. 1982. Cheats at work: an anthropology of workplace crime. London: Allen and Unwin.

National Health Service (NHS). 2003. Code of confidentiality. Leeds and London: National Health Service.

Peck, Edward and Perri 6. 2006. Beyond 'delivery': policy implementation as sense-making and settlement. Basingstoke: Palgrave Macmillan. 
Performance and Innovation Unit. 2002. Privacy and data sharing: the way forward for public services. London: Performance and Innovation Unit, Cabinet Office (now the Prime Minister's Strategy Unit).

Rayner, Steve. 1992. The cultural theory of risk. in Social theories of risk. eds Saul Krimsky and Dominic Golding, 83-116. Westport, Connecticut: Praeger.

Ritchie, Jean H QC, D Dick and R Langham. 1994. Ritchie Report: Report of the inquiry into the care and treatment of Christopher Clunis. London: HMSO.

Secretary of State for the Home Department. 2006. New powers against organised and financial crime. Cm 6875. London: Stationery Office.

SEU (Social Exclusion Unit). 2005. Inclusion through innovation: tackling social exclusion through new technologies. London: Department for Education and Skills.

Sullivan, Helen and Chris Skelcher. 2002. Working across boundaries: collaboration in public services. Basingstoke: Palgrave MacMillan.

Thompson, Michael. 1982a. A three dimensional model. in Essays in the sociology of perception, ed. Mary Douglas, 31-63. Routledge and Kegan Paul, London.

- 1992. The dynamics of cultural theory and implications for the enterprise culture. in Understanding the enterprise culture: themes in the work of Mary Douglas. eds. Shaun Hargreaves Heap and Angus Ross, 182-202. Edinburgh University Press, Edinburgh.

—, 1996. Inherent relationality: an anti-dualist approach to institutions. Los Senteret (Norwegian Research Centre in Organisation and Management), Bergen.

Thompson, Michael, Richard J Ellis and Aaron Wildavsky. 1990. Cultural theory. Boulder, Colorado: Westview Press.

Thompson, Michael, Per Selle and Gunnar Grendstad, eds. 1999. Cultural theory as political science. London: Routledge. 
Tilley, Nick. 2003. Community policing, problem-oriented policing and intelligence-led policing. in Handbook of policing. ed. Tim Newburn, 310-338. Cullompton, Devon: Willan Publishing. 


\section{Notes}

1 This research is funded by the Economic and Social Research Council: Project title: 'Joined-up public services: data sharing and privacy in multi-agency working'; ESRC Research Award no RES/000/23/0158. The authors are grateful to three anonymous referees for this journal for their comments and suggestions.

2 The analyses to be reported in this section should be read with the following four points in mind. First, the method used is not grounded theory or any similar "bottom up" method, but theory-driven coding of semi-structured interview text. All qualitative research that uses codes for open text data raises some challenges of replicability of coding in the hands of other researchers. However, we have sought to ensure replicability in two ways. Validity in coding has been pursued by relying on a set of criteria for regulation and integration. Reliability has been pursued with the use of intercoder reliability exercises and using reviews by senior researchers of all coding conducted by junior researchers in the team. The issue of replicability is most challenging in the more hybrid cases, for here fine judgments have to be made about the sequence of codes reflecting relative weight of institutional forms. Although we have sought to make these judgments in ways that faithfully reflect the underlying criteria for social regulation and social integration, in order to limit any danger of weakness in analysis, we have sought to rely in the aggregated summaries presented in the text on overall trends across the data set, rather than placing great weight on the finer judgments of relative weighting of forms within cases. Moreover, the nature of the sample means that it is better illustrative of diversity at the MAA level than at the organisation level. For this reason, we have eschewed any presentation of percentages of particular codes, and only used frequencies to illustrate our conclusions. Secondly, the analyses presented in this article involved extensive data reduction, which trades richness and particularity off for gain in case comparability. In another article (Bellamy et al, forthcoming), we present more quotations and generally a less reductive approach, and we show there that the same substantive results can be derived from that strategy of exploring the core hypotheses. Thirdly, the coding reflects snapshots of the organisations, teams and partnerships at the time of the interviews, and many of the cases were in flux or transition. Some of the hybrid forms shown in the coding reflect this fact: our aim has been to identify the forms predominant at the time. This means that hybrids are coded in the order of the institutional forms that appeared to be most important at the time of interview, and first or later positions in the sequence of codes are not used to indicate any expected emergent form. Fourth, we adopted the rule of coding the institutional form for the formally institutionalised unit of organisation in question - an organisation or a team (in other articles, we have also reported MAA level codes, but here we present the more finely grained analysis at organisation level). Of course, there are situations in many of the 
case studies where there are informal structures that are relatively strongly integrated, and which form subsets of formal organisations or teams, or else span more than just the organisation or team coded for. In such cases, an E or $\mathrm{H}$ code will typically appear in the sequence reporting the mix within the formal unit of organisation, but a quite different picture would have emerged if we had been able to code for informal strongly integrated units. However, this would have presented problems of consistency for comparative purposes, because it would have been difficult with the interview data alone in every case to be confident of the boundaries of such forms.

3 This research was granted ethical approval by a multi-site research ethics committee under the NHS Research Governance Framework. We applied for approval only for interview-based research. Even if we had had the resources to undertake analysis of actual case records in numbers that would have provided an adequate sample, this would have raised ethical problems. Almost certainly, this would not have been legally possible without the express individual consent of the patients, victims, in some cases relatives and suspected persons. To obtain that consent in enough cases exhibiting sufficient diversity to provide a suitably diverse sample would have been very difficult. Therefore, this strategy was not seriously considered.

${ }^{4}$ For reasons of space, a full set of data tables are not provided here, but they are available from the authors on request. 
Table 1: INSTITUTIONAL FORMS AND EXPECTED STYLES OF INFORMATION SHARING OR ABSENCE OF IT

\begin{tabular}{|c|c|c|}
\hline $\begin{array}{l}\text { Negative diagonal (isolate-enclave) } \\
\text { Information sharing or absence of } \\
\text { sharing defensively driven by } \\
\text { avoidance of risk }\end{array}$ & Weak social integration $\leftarrow$ & $\rightarrow$ Strong social integration \\
\hline Strong social regulation $\uparrow$ & $\begin{array}{l}\text { Isolate: coordination by individual coping with } \\
\text { constrained circumstance and brute luck; } \\
\text { Heavily constrained individuals acting } \\
\text { opportunistically, unable to sustain trust } \\
\text { Information sharing } \\
\text { Embraced as opportunistic coping } \\
\text { Rejection as inconvenient }\end{array}$ & $\begin{array}{l}\text { Hierarchy: coordination by rule, role and given fact; } \\
\text { Centrally ordered community } \\
\text { Information sharing } \\
\text { Undertaken as regulated practice } \\
\text { Rejection insofar as lack of formal governance for } \\
\text { sharing }\end{array}$ \\
\hline Weak social regulation $\downarrow$ & $\begin{array}{l}\text { Individualism: coordination by voluntary } \\
\text { agreement; instrumental, entrepreneurial } \\
\text { individuals } \\
\text { Information sharing } \\
\text { Commitment to sharing as managerial strategy } \\
\text { Rejection as inconvenience or threat to } \\
\text { managerial or professional control of resource }\end{array}$ & $\begin{array}{l}\text { Enclave: coordination by shared mutual commitment } \\
\text { within bounded group; internally egalitarian, but } \\
\text { sharply marked boundaries with others; held together } \\
\text { by shared commitment to moral principle } \\
\text { Information sharing } \\
\text { Embraced as crusade for saving lives etc } \\
\text { Rejection as in principle wrong }\end{array}$ \\
\hline $\begin{array}{l}\text { Positive diagonal (bierarchy- } \\
\text { individualism) } \\
\text { Information sharing or absence of } \\
\text { sharing positively driven by } \\
\text { commitment or pursuit of } \\
\text { opportunity }\end{array}$ & & \\
\hline
\end{tabular}

Proximate source; 6 et al. 2004, figures 3 and 4, pages 11 and 15 Ultimate sources: Douglas, 1982a [1978], 1982b, 1992, 1996; Gross and Rayner, 1986; Thompson et al. 1990; Durkheim, 1951 [1897] 


\section{Table 2: INSTITUTIONAL FORMS OF AGENCIES}

The derivation of the coding displayed below is described on p. 6-7 above. In columns 4 and 5, H refers to hierarchy, $\mathrm{E}$ to enclave, Is to Isolate and Ind to Individualist institutional forms. In columns 5 and 6 , Hi refers to high confidence, $\mathrm{M}$ to medium confidence and $\mathrm{L}$ to low confidence on the part of interviewees about data sharing and confidentiality across the MAA. In all cases, scores expressed are averages of all those expressed by interviewees in the relevant agency.

\begin{tabular}{|c|c|c|c|c|c|}
\hline $\begin{array}{l}\text { Agency } \\
\text { number }\end{array}$ & $\begin{array}{l}\text { Agency } \\
\text { function }\end{array}$ & $\begin{array}{l}\text { Agency by } \\
M A A \text { code } \\
\text { for } \\
\text { institutional } \\
\text { form }\end{array}$ & $\begin{array}{l}\text { Agency by } \\
\text { agency code } \\
\text { for } \\
\text { institutional } \\
\text { form }\end{array}$ & $\begin{array}{l}\text { Interviewee } \\
\text { confidence that } \\
\text { information } \\
\text { sharing in MAA is } \\
\text { adequate and } \\
\text { appropriate }\end{array}$ & $\begin{array}{l}\text { Interviewee } \\
\text { confidence that client } \\
\text { confidentiality is } \\
\text { adequately and } \\
\text { appropriately } \\
\text { respected in MAA }\end{array}$ \\
\hline
\end{tabular}

\begin{tabular}{|c|c|c|c|c|c|}
\hline \multicolumn{6}{|c|}{ MAA 1 - English health/social care for mental health - rural } \\
\hline $1 \mathrm{~A}$ & $\begin{array}{ll}\text { Merged } & \text { NHS } \\
\text { trust } & \end{array}$ & $\mathrm{H}$ & $\mathrm{H} / \mathrm{E}$ & Hi & $\mathrm{Hi}$ \\
\hline 1B & $\begin{array}{l}\text { Mental health } \\
\text { trust }\end{array}$ & $\mathrm{H}$ & $\mathrm{H} / \mathrm{E}$ & $\mathrm{M} / \mathrm{Hi}$ & $\mathrm{M} / \mathrm{Hi}$ \\
\hline 1EIT & $\begin{array}{l}\text { Early } \\
\text { intervention in } \\
\text { psychosis team }\end{array}$ & $\mathrm{E}$ & $\mathrm{E}$ & $\mathrm{Hi}$ & $\mathrm{M} / \mathrm{L}$ \\
\hline 1CMHT & $\begin{array}{l}\text { Community } \\
\text { mental health } \\
\text { team }\end{array}$ & $\mathrm{E} / \mathrm{H}$ & $\mathrm{E} / \mathrm{H}$ & Hi & $\mathrm{H}$ \\
\hline 1CRT & $\begin{array}{l}\text { Crisis } \\
\text { resolution team }\end{array}$ & $\mathrm{H}$ & $\mathrm{H}$ & Hi & Hi \\
\hline 1AOT & $\begin{array}{l}\text { Assertive } \\
\text { outreach team }\end{array}$ & $\mathrm{E} / \mathrm{In}$ & $\mathrm{E}$ & M & $\mathrm{Hi}$ \\
\hline 1C & $\begin{array}{l}\text { Local authority } \\
\text { social services } \\
\text { dept } \\
\text { (interviewee } \\
\text { based in } \\
\text { CMHT) }\end{array}$ & $\mathrm{H} / \mathrm{Is}$ & $\mathrm{Is} / \mathrm{H} / \mathrm{In} / \mathrm{E}$ & $\mathrm{Hi}$ & $\mathrm{Hi}$ \\
\hline \multicolumn{6}{|c|}{ MAA 2 English metropolitan health/social care for mental health } \\
\hline $2 \mathrm{~A}$ & $\begin{array}{l}\text { Mental health } \\
\text { trust }\end{array}$ & Is & Is & M & M \\
\hline 2CRT & $\begin{array}{l}\text { Crisis } \\
\text { resolution team }\end{array}$ & $\mathrm{H} / \mathrm{E}$ & $\mathrm{H}$ & L & $\mathrm{H}$ \\
\hline 2CMHT & $\begin{array}{l}\text { Community } \\
\text { mental health } \\
\text { team }\end{array}$ & Is/In & In/Is & $\mathrm{L} / \mathrm{M}$ & M \\
\hline 2EPS & $\begin{array}{l}\text { Emergency } \\
\text { psychiatric }\end{array}$ & Is/E & $\mathrm{E}$ & M & M \\
\hline
\end{tabular}




\begin{tabular}{|c|c|c|c|c|c|}
\hline \multicolumn{6}{|c|}{ service } \\
\hline 2B & $\begin{array}{l}\text { Local authority } \\
\text { social services } \\
\text { department }\end{array}$ & $\mathrm{In} / \mathrm{E}$ & Is/In & $\mathrm{L} / \mathrm{M}$ & M \\
\hline $\begin{array}{l}2 \mathrm{MH} \\
\text { Day }\end{array}$ & $\begin{array}{l}\text { Mental health } \\
\text { day care centre }\end{array}$ & $\mathrm{E} / \mathrm{H}$ & $\mathrm{E} / \mathrm{H}$ & $\mathrm{L} / \mathrm{M}$ & $\mathrm{M} / \mathrm{Hi}$ \\
\hline \multicolumn{6}{|l|}{ Centre } \\
\hline $2 \mathrm{AOT}$ & $\begin{array}{l}\text { Assertive } \\
\text { outreach team }\end{array}$ & $\mathrm{E} / \mathrm{In}$ & $\mathrm{E}$ & $\mathrm{L} / \mathrm{M}$ & $\mathrm{M} / \mathrm{Hi}$ \\
\hline $2 \mathrm{C}$ & $\begin{array}{l}\text { National charity } \\
\text { for mental } \\
\text { health }\end{array}$ & $\mathrm{E}$ & $\mathrm{E}$ & $\mathrm{L} / \mathrm{M}$ & $\mathrm{M} / \mathrm{Hi}$ \\
\hline \multicolumn{6}{|c|}{ MAA 3 English metropolitan H/SC for older people } \\
\hline $3 \mathrm{~A}$ & $\begin{array}{l}\text { Local Authority } \\
\text { social services } \\
\text { department }\end{array}$ & $\mathrm{H}$ & $\mathrm{H} / \mathrm{E}$ & $\mathrm{L}$ & M \\
\hline 3B & $\begin{array}{l}\text { Primary care } \\
\text { trust }\end{array}$ & $\mathrm{H}$ & $\mathrm{H} / \mathrm{E}$ & $\mathrm{L} / \mathrm{M}$ & M \\
\hline $3 \mathrm{C}$ & $\begin{array}{l}\text { Local older } \\
\text { person's charity }\end{array}$ & $\mathrm{In} / \mathrm{E}$ & $\mathrm{E}$ & $\mathrm{Hi}$ & $\mathrm{M} / \mathrm{Hi}$ \\
\hline 3D & $\begin{array}{l}\text { National charity } \\
\text { for the elderly }\end{array}$ & $\mathrm{E} / \mathrm{In}$ & $\mathrm{E} / \mathrm{Is}$ & $\mathrm{L} / \mathrm{M}$ & M \\
\hline $3 \mathrm{E}$ & Housing & $\mathrm{H} / \mathrm{E}$ & H/E & $\mathrm{Hi}$ & $\mathrm{M} / \mathrm{Hi}$ \\
\hline \multicolumn{6}{|c|}{ MAA 4 Eng;lish urban H/SC for older peope } \\
\hline $4 \mathrm{~A}$ & $\begin{array}{l}\text { Primary care } \\
\text { trust }\end{array}$ & $\mathrm{H} / \mathrm{Is}$ & $\mathrm{H}$ & $\mathrm{M} / \mathrm{Hi}$ & $\mathrm{M} / \mathrm{Hi}$ \\
\hline $4 B$ & Social services & Is/ $\mathrm{H}$ & $\mathrm{H} / \mathrm{Is}$ & $\mathrm{M} / \mathrm{Hi}$ & $\mathrm{M} / \mathrm{Hi}$ \\
\hline $4 \mathrm{C}$ & $\begin{array}{l}\text { National charity } \\
\text { for the elderly }\end{array}$ & $\mathrm{E} / \mathrm{Is}$ & $\mathrm{H}$ & $\mathrm{L} / \mathrm{M}$ & $\mathrm{M}$ \\
\hline $4 \mathrm{E}$ & $\begin{array}{l}\text { LA housing, } \\
\text { (arms length } \\
\text { mgt org) }\end{array}$ & Is/H & $\mathrm{In} / \mathrm{E}$ & $\mathrm{L} / \mathrm{M}$ & $\mathrm{L} / \mathrm{M}$ \\
\hline \multicolumn{6}{|c|}{ MAA 5 Engish metropolitan CDRP } \\
\hline $5 \mathrm{~A}$ & $\begin{array}{l}\text { Local authority } \\
\text { community } \\
\text { safety } \\
\text { department }\end{array}$ & $\mathrm{H} / \mathrm{Is} / \mathrm{Ind}$ & Ind $/ \mathrm{H}$ & M & M \\
\hline 5DAT & $\begin{array}{l}\text { Drug action } \\
\text { team }\end{array}$ & $\mathrm{E} / \mathrm{H} / \mathrm{Is}$ & E & $\mathrm{L} / \mathrm{M}$ & $\mathrm{L} / \mathrm{M}$ \\
\hline $5 B$ & $\begin{array}{l}\text { Police } \\
\text { (community } \\
\text { safety dept) }\end{array}$ & $\mathrm{In} / \mathrm{H} / \mathrm{Is}$ & $\mathrm{H} / \mathrm{In}$ & $\mathrm{M} / \mathrm{L}$ & $\mathrm{M} / \mathrm{L}$ \\
\hline $5 \mathrm{C}$ & $\begin{array}{l}\text { Sub regional } \\
\text { information } \\
\text { services } \\
\text { partnership }\end{array}$ & $\mathrm{H} / \mathrm{Is} / \mathrm{E}$ & $\mathrm{H}$ & $\mathrm{M} / \mathrm{Hi}$ & M \\
\hline 5D & Fire & Is $/ \mathrm{H}$ & $\mathrm{H} / \mathrm{In}$ & $\mathrm{M}$ & $\mathrm{Hi}$ \\
\hline $5 \mathrm{E}$ & $\begin{array}{l}\text { Children's } \\
\text { charity - sex } \\
\text { abuse project }\end{array}$ & $\mathrm{H} / \mathrm{E}$ & $\mathrm{E} / \mathrm{H}$ & M & $\mathrm{Hi}$ \\
\hline $5 F$ & $\begin{array}{l}\text { Strategic health } \\
\text { authority - } \\
\text { prisons service }\end{array}$ & $\mathrm{H} /$ Ind & $\mathrm{E} / \mathrm{H}$ & $\mathrm{L} / \mathrm{M}$ & $\mathrm{L} / \mathrm{M}$ \\
\hline $5 G$ & $\begin{array}{l}\text { Primary health } \\
\text { care - specialist } \\
\text { drug abuse } \\
\text { medical practice }\end{array}$ & $\mathrm{E}$ & $\mathrm{H} / \mathrm{E}$ & $\mathrm{L}$ & $\mathrm{L}$ \\
\hline
\end{tabular}




\begin{tabular}{|c|c|c|c|c|c|}
\hline 5 YOS & $\begin{array}{l}\text { Youth } \\
\text { offending } \\
\text { service }\end{array}$ & Is/Ind/H & Is $/ \mathrm{H}$ & $\mathrm{L} / \mathrm{M}$ & $\mathrm{L}$ \\
\hline \multicolumn{6}{|c|}{ MAA 6 - English rural CDRP } \\
\hline $6 \mathrm{~A}$ & $\begin{array}{l}\text { County council } \\
\text { community } \\
\text { safety } \\
\text { department }\end{array}$ & Is $/ \mathrm{H}$ & Is $/ H$ & $\mathrm{M}$ & $\mathrm{M}$ \\
\hline 6YOS & $\begin{array}{l}\text { Youth } \\
\text { offending } \\
\text { service }\end{array}$ & $\mathrm{E} / \mathrm{H}$ & $\mathrm{E} / \mathrm{H} / \mathrm{Is}$ & $\mathrm{M}$ & $\mathrm{M}$ \\
\hline 6B & $\begin{array}{l}\text { Local authority } \\
\text { community } \\
\text { safety }\end{array}$ & Is & Is $/ H$ & $\mathrm{~L} / \mathrm{M}$ & $\mathrm{L} / \mathrm{M}$ \\
\hline 6C & Fire service & Is $/ \mathrm{H}$ & In & M & $\mathrm{M}$ \\
\hline 6D & Police service & Is & $\mathrm{Is} / \mathrm{In} / \mathrm{E} / \mathrm{H}$ & $\mathrm{L}$ & $\mathrm{L}$ \\
\hline $6 \mathrm{E}$ & $\begin{array}{l}\text { National drug } \\
\text { abuse charity }\end{array}$ & $\mathrm{E} / \mathrm{H}$ & $\mathrm{H}$ & $\mathrm{M}$ & $\mathrm{Hi}$ \\
\hline $6 \mathrm{~F}$ & $\begin{array}{l}\text { Primary care } \\
\text { trust }\end{array}$ & $\mathrm{Is} / \mathrm{In} / \mathrm{H} / \mathrm{E}$ & Is & $\mathrm{M}$ & $\mathrm{Hi} / \mathrm{M}$ \\
\hline 6DAAT & $\begin{array}{l}\text { County drug } \\
\text { and alcohol } \\
\text { action team }\end{array}$ & $\mathrm{H} / \mathrm{Is}$ & $\mathrm{H} / \mathrm{Is}$ & $\mathrm{M}$ & $\mathrm{L} / \mathrm{M}$ \\
\hline $6 \mathrm{H}$ & $\begin{array}{l}\text { County } \\
\text { information } \\
\text { partnership }\end{array}$ & $\mathrm{H}$ & $\mathrm{H}$ & $\mathrm{L} / \mathrm{M}$ & $\mathrm{L} / \mathrm{M}$ \\
\hline \multicolumn{6}{|c|}{ MAA 7 English mixed urban/rural MAPPA } \\
\hline 7A & Probation & $\mathrm{H} / \mathrm{Ind}$ & $\mathrm{H} / \mathrm{Is}$ & $\mathrm{Hi} / \mathrm{M}$ & $\mathrm{Hi} / \mathrm{M}$ \\
\hline 7B & $\begin{array}{l}\text { Housing } \quad- \\
\text { tenancy } \\
\text { compliance } \\
\text { team }\end{array}$ & Is/Ind/H & $\mathrm{E} / \mathrm{H} / \mathrm{Is}$ & $\mathrm{M} / \mathrm{L}$ & $\mathrm{L} / \mathrm{M}$ \\
\hline 7YOS & $\begin{array}{l}\text { Youth Offending } \\
\text { Service }\end{array}$ & $\mathrm{H} / \mathrm{Is}$ & Is $/ \mathrm{H}$ & $\mathrm{M} / \mathrm{Hi}$ & $\mathrm{M} / \mathrm{L}$ \\
\hline $7 \mathrm{D}$ & $\begin{array}{l}\text { Housing } \quad- \\
\text { tenancy } \\
\text { compliance } \\
\text { team }\end{array}$ & Is/H/Ind & $\mathrm{H} / \mathrm{Is} / \mathrm{Ind}$ & $\mathrm{M} / \mathrm{Hi}$ & $\mathrm{Hi} / \mathrm{M}$ \\
\hline $7 \mathrm{E}$ & Police service & $\mathrm{In} / \mathrm{Is} / \mathrm{E}$ & $\mathrm{H} / \mathrm{In}$ & M & $\mathrm{M} / \mathrm{Hi}$ \\
\hline $7 F$ & $\begin{array}{l}\text { Probation } \\
\text { secondees to } \\
\text { prison service }\end{array}$ & $\mathrm{H} / \mathrm{Is}$ & $\mathrm{H} / \mathrm{Ind} / \mathrm{E}$ & $\mathrm{Hi} / \mathrm{M}$ & $\mathrm{M}$ \\
\hline $7 \mathrm{G}$ & $\begin{array}{l}\text { Mental health } \\
\text { trust }\end{array}$ & $\mathrm{E} / \mathrm{H} / \mathrm{Ind}$ & $\mathrm{E} / \mathrm{H} / \mathrm{Is}$ & $\mathrm{M}$ & $\mathrm{M} / \mathrm{L}$ \\
\hline \multicolumn{6}{|c|}{ MAA 8 English metropolitan MAPPA } \\
\hline $8 \mathbf{A}$ & $\begin{array}{l}\text { Probation } \\
\text { service }\end{array}$ & $\mathrm{H} / \mathrm{Is}$ & $\mathrm{H} / \mathrm{Is}$ & $\mathrm{M} / \mathrm{Hi}$ & $\mathrm{Hi} / \mathrm{M}$ \\
\hline $8 B$ & $\begin{array}{l}\text { Police }- \text { Violent } \\
\text { and sex } \\
\text { offenders unit }\end{array}$ & Is-In/E & $\mathrm{H} / \mathrm{In} / \mathrm{E}$ & $\mathrm{M}$ & M \\
\hline $8 \mathrm{C}$ & Prison service & $\mathrm{Is} / \mathrm{In} / \mathrm{H}$ & $\mathrm{H} / \mathrm{Is}$ & M & $\mathrm{M}$ \\
\hline $8 \mathrm{D}$ & Victim support & $\mathrm{H} / \mathrm{Is}$ & $\mathrm{H} / \mathrm{Is}$ & $\mathrm{M} / \mathrm{L}$ & $\mathrm{Hi}$ \\
\hline $8 \mathrm{E}$ & $\begin{array}{l}\text { Housing - } \\
\text { registered social } \\
\text { landlord }\end{array}$ & $\mathrm{H} / \mathrm{Ind} / \mathrm{Is}$ & $\mathrm{H} / \mathrm{E}$ & $\mathrm{M} / \mathrm{L}$ & $\mathrm{M}$ \\
\hline $8 F$ & $\begin{array}{l}\text { Primary Care } \\
\text { Trust - public }\end{array}$ & $\mathrm{E} / \mathrm{H}$ & Is $/ H / E$ & M & $\mathrm{M} / \mathrm{L}$ \\
\hline
\end{tabular}




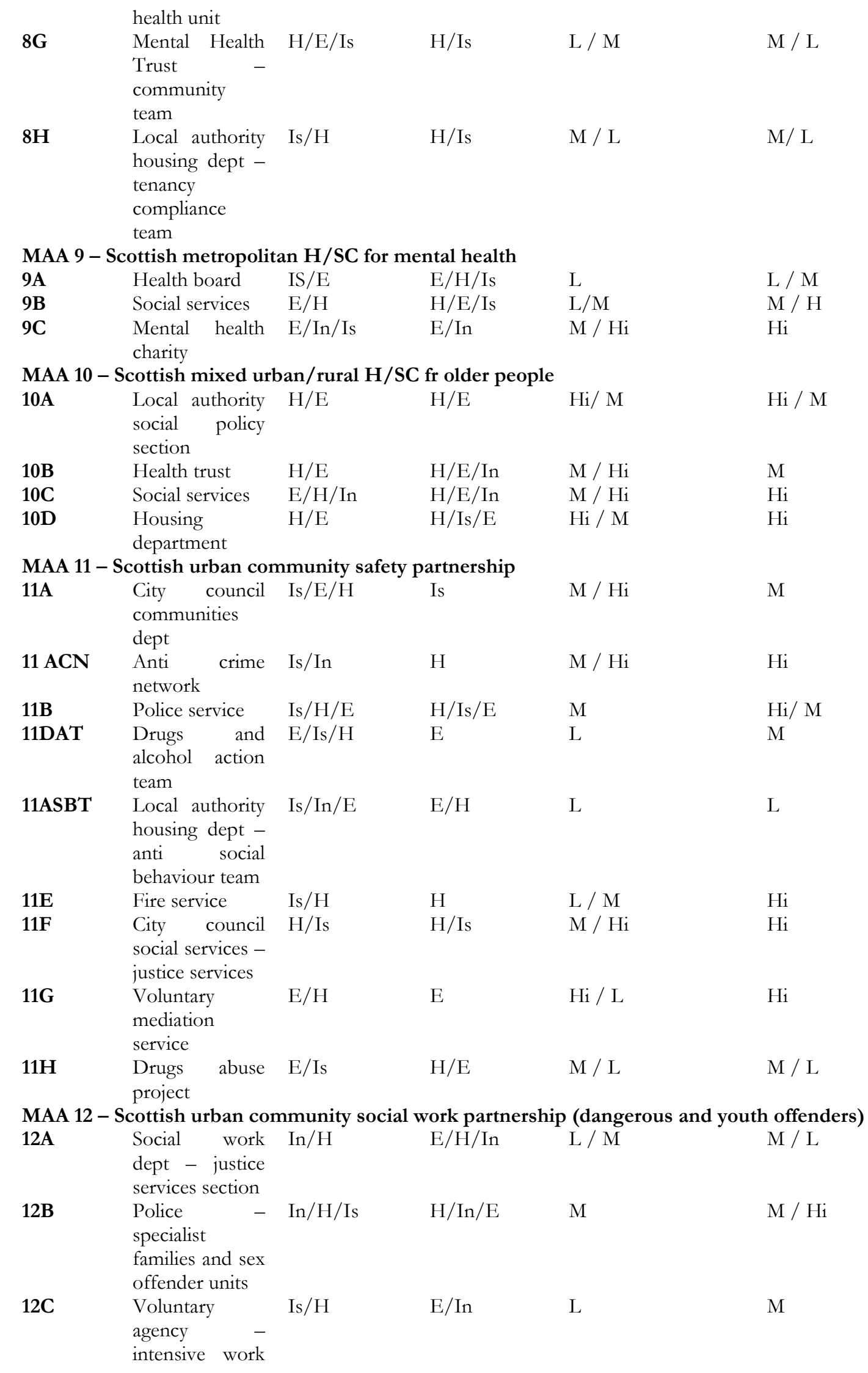


with selected

youth offenders Local authority housing dept temporary accommodatio

n management

unit 


\section{Table 3: STYLE OF INFORMATION SHARING}

\begin{tabular}{|c|c|c|c|}
\hline $\begin{array}{l}M \\
A A\end{array}$ & $\begin{array}{l}\text { Electronic records, } \\
\text { paper or both }\end{array}$ & $\begin{array}{l}\text { Whose data are } \\
\text { shared }\end{array}$ & How data are organised \\
\hline 1 & chiefly paper & $\mathrm{H} / \mathrm{SC}$ patient & Depends on team and/or locality \\
\hline 2 & paper, electronic & $\mathrm{H} / \mathrm{SC}$ patient & $\begin{array}{l}\text { Some electronic DS schemes being } \\
\text { piloted by social services }\end{array}$ \\
\hline 3 & paper & $\mathrm{H} / \mathrm{SC}$ patient & $\begin{array}{llcc}\text { Electronic } & \text { version } & \text { of } & \text { Single } \\
\text { Assessment } & \text { Process } & \text { (SAP) being } \\
\text { piloted. } & & & \end{array}$ \\
\hline 4 & paper, electronic & $\mathrm{H} / \mathrm{SC}$ patient & $\begin{array}{l}\text { PCT and social services have } \\
\text { separate databases, but in some } \\
\text { mulit professional teams there are } \\
\text { staff with some access to each in } \\
\text { course of joint case management. } \\
\text { Awaiting benefits of NPfIT (now } \\
\text { Connecting for Health) }\end{array}$ \\
\hline 5 & paper, electronic & $\begin{array}{l}\text { Offender, } \\
\text { victim, } \\
\text { sometimes } \\
\text { witnesses }\end{array}$ & $\begin{array}{l}\text { Most data transferred in aggregated } \\
\text { (but not always anonymised) form } \\
\text { to populate local, sub regional, } \\
\text { regional and national databases, } \\
\text { used for crime analysis, reporting } \\
\text { and operational purposes. Most } \\
\text { data transferred through sub } \\
\text { regional strategic/analytical body, } \\
\text { not shared direct from agency to } \\
\text { agency }\end{array}$ \\
\hline 6 & paper, electronic & $\begin{array}{l}\text { Offender, } \\
\text { victim, } \\
\text { sometimes } \\
\text { witnesses }\end{array}$ & $\begin{array}{l}\text { Some partners share aggregated } \\
\text { crime data in a joint repository; } \\
\text { otherwise, data kept in partners } \\
\text { own records }\end{array}$ \\
\hline 7 & $\begin{array}{l}\text { paper, } \\
\text { electronic, verbal }\end{array}$ & $\begin{array}{l}\text { Offender; } \\
\text { victim, client }\end{array}$ & $\begin{array}{l}\text { Data from records shared at regular } \\
\text { multilateral meetings of agencies on } \\
\text { a case by case basis; some data also } \\
\text { shared bilaterally for the purposes } \\
\text { of formal risk assessments or case } \\
\text { management. }\end{array}$ \\
\hline 8 & $\begin{array}{l}\text { paper, } \\
\text { electronic, verbal } \\
\text { - email used a } \\
\text { great deal }\end{array}$ & $\begin{array}{l}\text { Offender; } \\
\text { victim, client }\end{array}$ & $\begin{array}{l}\text { Data from records shared at regular } \\
\text { multilateral meetings of agencies on } \\
\text { a case by case basis; some data also } \\
\text { shared bilaterally for the purposes } \\
\text { of formal risk assessments or case } \\
\text { management. }\end{array}$ \\
\hline 9 & $\begin{array}{l}\text { paper, } \\
\text { electronic, verbal }\end{array}$ & HSC patient & $\begin{array}{l}\text { NHS use PIMS, LASW use } \\
\text { CareFirst data systems; two } \\
\text { agencies have different data } \\
\text { retention periods and rules for } \\
\text { paper and electronic data. } \\
\text { Protocols are mainly within-agency. } \\
\text { Case alerting flags are not } \\
\text { consistently used. }\end{array}$ \\
\hline
\end{tabular}

Scope of access to information beld by other agenciess (routine for whole database, caseby-case authorisation)

At discretion of individual rather than
via formal procedure.

At agency or team level, access at discretion of individual

Routine for whole database

Referral is major point of sharing. Case-by-case decisions about access are generally routine, although exceptional cases referred to Caldicott Guardian. Single Assessment Process is expected to simplify this.

No access to records held by other agencies in partnership. Most data is shared routinely according to clear protocols. Partners receive agreed data sets in return.

Routine, with exception of anti-social behaviour data

Police and probation share common records in a joint unit, and probation officers have direct access to the police national sex/violent offender database (ViSOR). Probation officers located in prisons have access to prison records and case management system. All other sharing is at discretion of agency that owns the record.

Probation officers have direct access to the police national sex/violent offender database (ViSOR). All other sharing is at discretion of agency that owns the record.

NHS and SW staff have no automatic shared access rights to each other's databases; different practices in each locality within city. Sharing is mainly within teams, some specialists among which are multi-professional. Some teams allow read-only access to "tombstone data" for other profession. Single Shared Assessment not yet achieved. Since SW withdrew from joint resource centres and $\mathrm{HO}$ team, most sharing is on case-by-case 


\begin{tabular}{|c|c|c|c|c|}
\hline 10 & $\begin{array}{l}\text { Paper, verbal, } \\
\text { electronic and } \\
\text { increasingly to } \\
\text { be pooled }\end{array}$ & $\begin{array}{l}\text { HSC; older } \\
\text { people at first }\end{array}$ & $\begin{array}{l}\text { Some agencies will soon share } \\
\text { client data in a joint repository; } \\
\text { otherwise, data kept in partners' } \\
\text { own records; identifiable basic data } \\
\text { and often 'sensitive' data }\end{array}$ & $\begin{array}{l}\text { requested basis. } \\
\text { Much bilateral and 'need to know' } \\
\text { sharing, determined by routines and } \\
\text { frontline judgement, but asymmetric } \\
\text { volume of flow between certain } \\
\text { agencies and/or teams; emphasis on } \\
\text { gaining client consent; protocols } \\
\text { being devised }\end{array}$ \\
\hline 11 & $\begin{array}{l}\text { Paper, } \\
\text { electronic, verbal }\end{array}$ & $\begin{array}{l}\text { Offender, } \\
\text { victim, client }\end{array}$ & $\begin{array}{l}\text { Agencies maintain various case } \\
\text { management records and offender } \\
\text { databases. None pooled or shared. } \\
\text { Some data shared for analytical } \\
\text { purposes, usually in anonymised } \\
\text { form. }\end{array}$ & $\begin{array}{l}\text { Sharing is at discretion of frontline } \\
\text { staff or their managers, for purposes } \\
\text { of case management or to plan crime } \\
\text { prevention strategies. Retail crime } \\
\text { offender database provides access to } \\
\text { police according to strict protocols. }\end{array}$ \\
\hline 12 & $\begin{array}{l}\text { Paper, verbal, } \\
\text { electronic }\end{array}$ & $\begin{array}{l}\text { Offender, } \\
\text { victim, client }\end{array}$ & $\begin{array}{l}\text { Agencies maintain various case } \\
\text { management records and offender } \\
\text { databases. None pooled or shared. } \\
\text { Some data shared for analytical } \\
\text { purposes, usually in anonymised } \\
\text { form. }\end{array}$ & $\begin{array}{l}\text { Sharing is at discretion of frontline } \\
\text { staff or their managers, for purposes } \\
\text { of case management and formal risk } \\
\text { assessments. Personal data is also } \\
\text { shared for purposes of writing court } \\
\text { reports. }\end{array}$ \\
\hline
\end{tabular}

